\title{
The Central Role of Renal Microcirculatory Dysfunction in the Pathogenesis of Acute Kidney Injury
}

\author{
Can Ince \\ Department of Translational Physiology, Academic Medical Center, Amsterdam, The Netherlands
}

\section{Key Words}

Renal failure $\cdot$ Microcirculation $\cdot$ Oxygenation $\cdot$ Reactive oxygen species $\cdot$ Nitric oxide

\begin{abstract}
Acute kidney injury (AKI) is a rapidly developing condition often associated with critical illness, with a high degree of morbidity and mortality, whose pathophysiology is ill understood. Recent investigations have identified the dysfunction of the renal microcirculation and its cellular and subcellular constituents as being central to the etiology of AKI. Injury is caused by inflammatory activation involving endothelial leucocyte interactions in combination with dysregulation of the homeostatis between oxygen, nitric oxide, and reactive oxygen species. Effective therapies expected to resolve AKI will have to control inflammation and restore this homeostasis. In order to apply and guide these therapies effectively, diagnostic tools aimed at physiological biomarkers of AKI for monitoring renal microcirculatory function in advance of changes in pharmacological biomarkers associated with structural damage of the kidney will need to be developed.

(c) 2014 S. Karger AG, Basel
\end{abstract}

Changing Paradigms in Acute Kidney Injury: From Mechanisms to Management - Proceedings of the 5th Annual UAB-UCSD O'Brien Center Symposium (San Diego, Calif., USA, March 4, 2014). (c) 2014 S. Karger AG, Basel

$1660-2110 / 14 / 1274-0124 \$ 39.50 / 0$
Despite the identification of several cellular mechanisms thought to underlie the development of acute kidney injury (AKI), the pathophysiology of the occurrence of AKI is still ill understood [1]. It is clear, however, that instead of a single mechanism being responsible for its etiology, an orchestra of cellular mechanisms in complex interaction with inflammatory, oxidative, and nitrosative factors account for the path leading to renal failure [2-4]. The integrative physiological compartment where these mechanisms come together and exert their deleterious effect is the renal microcirculation $[3,4]$. That is why the study of the renal microcirculation and identification of the determinants of its (dys)function in models of AKI are essential for providing insight into the pathogenesis and resolution of AKI. Based on such research, it is expected that translational clinical investigations will provide novel strategies to resolve AKI and equally important new renal monitoring modalities based on physiological markers of AKI to identify and guide these novel therapeutic strategies [5].

The factors responsible for renal microcirculatory dysfunction in advance of AKI include a combination of inflammatory and/or hypoxemic insults that cause activation of leucocytes and/or inflammatory mediators which affect all aspects of normal renal microcirculation essential for the function of the kidney. In this sequence of events, the normal homeostasis between oxygen, nitric

\section{KARGER}

E-Mail karger@karger.com www.karger.com/nec
Dr. Can Ince

van der Tasstraat

NL-2312 AG Amsterdam (The Netherlands)

E-Mail c.ince@amc.nl 
oxide, and reactive oxygen species governing renal signaling, (micro)vascular function, and cellular respiration gets out of balance and the levels of oxygen, nitric oxide, and reactive oxygen species take on a pathogenic role, ultimately leading to renal failure [6]. Renal cellular and subcellular structures essential for renal function are injured by these reactive mediators, leading to lipid peroxidation and the loss of renal tubular cell polarity, as well as altered glomerular filtration.

A main determinant of renal function is the sustained adequate supply and utilization of oxygen at the microcirculatory and mitochondrial level [7]. The highly complex architecture of the renal microvasculature, the need to meet a high energy demand, and the fact that the kidney is borderline ischemic make the kidney an organ highly vulnerable to hypoxic injury. Under normal, steady-state conditions, the oxygen supply to the renal tissues is well regulated in order to meet the oxygen requirements of the kidney to produce ATP through mitochondrial oxidative phosphorylation. The kidney requires a relatively high amount of oxygen to meet its functional needs (approx. 7\% of the total body oxygen consumption), most of which is used by the tubular cells for solute reabsorption [8]. However, under pathological conditions, such as during ischemia-reperfusion, shock, or sepsis, the delicate balance of oxygen supply versus demand is disturbed due to renal microvasculature dysfunction [9]. Microcirculatory dysfunction impedes renal microcirculatory flow at the regional level and this leads to the occurrence of hypoxemic pockets especially in the renal cortex, which is highly heterogeneous even following resuscitation procedures [10]. In this context, hypoxemia is regarded as a key characteristic of and contributing factor to AKI [7]. The identification of this hypoxemic component in models of AKI, however, has been elusive due to this heterogeneity and the limitation of tissue oxygenation techniques such as oxygen electrodes which lack the ability to detect this heterogeneity in tissue oxygen levels. Such measurements have missed this hypoxemic component of AKI, resulting in the mistaken interpretation that hypoxemia does not play a role in the understanding of AKI. Techniques, such as histogram analysis of the Pd phosphorescence technique [11] and immunostaining of pimonidazole, able to detect hypoxemic areas in stained histological sections $[12,13]$ have identified the heterogeneous hypoxemic nature of AKI. This is an important observation because it explains how hemodynamic alterations in the kidney microcirculation, independently of the global renal arterial flow, can sustain an inflammatory state. Here, the heterogeneously present

The Role of Renal Microcirculatory Dysfunction in the Pathogenesis of AKI capillary flow sustains weak microcirculatory units where reperfusion injury at hypoxia-normoxia borders sustains a continuous state of inflammation.

States of reperfusion injury induce leucocyte activation $[14,15]$ and the generation of reactive oxygen species by enzyme systems such as $\mathrm{NADP}(\mathrm{H})$ and xanthine oxidase [16]. These are key pathogenic events which lead to microcirculatory dysfunction that results in AKI. Many experimental studies have shown that therapeutic interventions targeting reactive oxygen species have a favorable course in the prevention of AKI [17]. Examples of such therapeutic interventions include $\mathrm{N}$-acetylcysteine [18] and vitamin C [19]. Intricately associated with oxidative stress is the activation of nitric oxide pathways. Nitrosative stress is mainly associated with the inflammation-induced activation of the inducible nitric oxide enzyme system. Several studies have shown that inhibition of inducible nitric oxide also has a favorable effect on the prevention of AKI. Such compounds have included specific inducible nitric oxide blockade by L-NIL [20, 21] but also more general anti-inflammatory compounds such as dexamethasone [22]. Interactions between the NO system and oxidative radicals fuel the factors responsible for renal injury [23]. An example of the interaction between nitric oxide and reactive oxygen species is the uncoupling of eNOS by the depletion of tetrahydrobiopterin (BH4), which results in the generation of superoxide. Experimental studies supplementing the $\mathrm{BH} 4$ precursor sepiapterin have shown such a therapeutic maneuver to be protective in the progression to renal failure [24]. Taking the above information into consideration, we developed an integrative pathophysiological model of AKI whereby inflammatory activation associated with leucocyte activation and endothelial dysfunction interacts with alterations in the homeostasis of the balance between oxygen and reactive oxygen and nitrosative species to fuel the progress to AKI. This integrative pathogenic scenario can be fueled by many factors and acts as a highly toxic hit causing destruction of renal cellular and subcellular structures and opening the door to renal failure $[4,6]$.

Besides known inflammatory hits such as radiocontrast agents, reperfusion injury, and sepsis contributing to the evolution of cellular and microcirculatory injury which leads to AKI, the inappropriate use of standard therapies in the care of the critically ill can also contribute to renal failure. The main such therapeutic modality concerns the inappropriate use of fluid therapy [25]. Fluid therapy for the treatment of hypovolemia, when administered inappropriately, can promote hypoxemia by ex- 
cess hemodilution [26]. Fluids, though effective at promoting tissue hypoperfusion associated with hypovolemia, are poor oxygen carriers and ineffective at promoting tissue oxygenation. We showed this to be the case in a study where we compared the administration of crystalloid resuscitation in a shock model to blood resuscitation. That study showed that, though effective at correcting systemic blood pressure variables, these fluids were highly ineffective at correcting renal tissue oxygenation [27]. In addition, fluids can promote oxidative and inflammatory activation, both of which are deleterious to renal function $[28,29]$. The composition of fluids should also be taken into consideration as a contributing factor for AKI. The most used fluid in resuscitation, i.e. $0.9 \% \mathrm{NaCl}$, has been especially implicated in this respect and its use as a resuscitation fluid is a subject of controversy [30,31]. It is clear, however, that the administered volume is the key issue that determines the extent to which fluid therapy is deleterious to renal function. Conventionally used hemodynamic targets are based on systemic hemodynamic variables and it is clear that hitting such targets may result in excessive fluid administration. Thus, a new paradigm is needed for a rationale centered on the true target to correct hypovolemia by fluid administration, which is the correction by fluids of microcirculatory hypoperfusion. It is expected that targeting such a variable will result in less fluid administration and contribute to the reduction of renal failure among critically ill patients [32].

A main contributing factor in the propagation of pathogenic insults leading to AKI has been suggested to be mitochondrial dysfunction. In a unified approach, Gomez et al. [33] identified mitochondrial dysfunction as a key contributor to the development of AKI. Mitochondrial function is critical not only for the production of ATP needed for sodium reabsorption but also because of its role as a prime generator of oxygen radicals during oxidative phosphorylation. Insults associated with the development of AKI, such as sepsis, have been recently shown to inactivate important physiological defense mechanisms such as the presence of manganese superoxide, reducing the endogenous defense capacity of renal cells and promoting oxidative stress [34]. Such increased oxidative stress, besides promoting lipid peroxidation, can in turn be deleterious to mitochondrial function by increasing the levels of mitochondrial uncoupling protein which promotes mitochondrial $\mathrm{H}^{+}$leakage, depolarizing the mitochondrial membrane potential needed to drive oxidative phosphorylation and thereby inhibiting mitochondrial ATP production [35].
A central cellular victim of the pathogenic factors leading to AKI is the endothelial cell [36], and its most vulnerable component is one of its subcellular structures called the glycocalyx. The glycocalyx is a thick gel-like $(0.2-\mu \mathrm{m})$ layer coating the vascular lumen side of the endothelial cells of the capillaries. Embedded in the glycocalyx are important molecular systems essential for antioxidant defense and hemostasis as well as signal transduction responsible for vascular (auto)regulation [37]. Reactive oxygen species are one of the main culprits in shedding of the glycocalyx, promoting leucocyte adhesion, compromising the endothelial barrier, and causing glomerular filtration dysfunction [38]. During septic renal failure, the glycocalyx is disrupted by the factors described above, leading to albuminuria [39]. In addition to such structures being destroyed in the processes leading to AKI, transmembrane molecules essential for cellular integrity and communication are also compromised. Such molecules include tight junctions, important for the maintenance of tubular polarity [40], and gap junctions, important for cellular communication essential for the integrative control of renal functions [41].

It is becoming clear that, in order for therapeutic strategies to be effective at resolving AKI, a multimodal approach is needed in which tissue oxygenation is improved by resolution of the heterogeneous hypoxic areas; moreover, control of inflammation is needed and integrative correction of the homeostasis between nitric oxide and reactive oxygen species needs to be established. Although such an integrative therapeutic approach would require several therapeutic interventions, we have shown in experimental studies that a number of drugs have such multimodal therapeutic effects, which is in line with the concepts outlined above. These drugs include: iloprost, dexamethasone, activated protein $\mathrm{C}$, seperatine, and vitamin C $[22,24,42,43]$. In order to translate these preclinical concepts to critically ill patients in danger of developing AKI, new clinical monitors of physiological biomarkers of AKI will have to be further developed [5].

\section{Acknowledgment}

The current paper was based on insights obtained from research work supported by the Dutch Kidney Foundation (grant C 09.2290) (Bussum, The Netherlands). 


\section{Disclosure Statement}

Dr. Ince has received honoraria and independent research grants from Fresenius-Kabi (Bad Homburg, Germany), Baxter Health Care (Deerfield, Ill., USA), AM-Pharma (Bunnik, The Netherlands), Novartis (Basel, Switzerland), Hutchinson(Hutchinson, Minn., USA), B. Braun (Melsungen, Germany), Covidien
(Dublin, Ireland), and Eli Lilly (Indianapolis, Ind., USA). He has been a consultant for MicroVision Medical in the past but has not had any contact with this company for more than 4 years, and he has no competing interests other than his commitment to promoting the importance of microcirculation in the care of critically ill patients.

\section{References}

1 Wan L, Bagshaw SM, Langenberg C, Saotome T, May C, Bellomo R: Pathophysiology of septic acute kidney injury: what do we really know? Crit Care Med 2008;36(suppl 4):S198S203.

$\checkmark 2$ Matejovic M, Radermacher P, Joannidis M: Acute kidney injury in sepsis: is renal blood flow more than just an innocent bystander? Intensive Care Med 2007;33:1498-1500.

-3 Bonventre JV, Yang L: Cellular pathophysiology of ischemic acute kidney injury. J Clin Invest 2011;121:4210-4221.

-4 Ergin B, Kapucu A, Demirci-Tansel C, Ince C: The renal microcirculation in sepsis. Nephrol Dial Transplant 2014, DOI: 10.1093/ndt/ gfu105.

$\checkmark 5$ Okusa MD, Jaber BL, Doran P, Duranteau J, Yang L, Murray PT, Mehta RL, Ince C: Physiological biomarkers of acute kidney injury: a conceptual approach to improving outcomes. Contrib Nephrol 2013;182:65-81.

-6 Aksu U, Demirci C, Ince C: The pathogenesis of acute kidney injury and the toxic triangle of oxygen, reactive oxygen species and nitric oxide. Contrib Nephrol 2011;174:119-128.

7 Evans RG, Ince C, Joles JA, Smith DW, May CN, O'Connor PM, Gardiner BS: Haemodynamic influences on kidney oxygenation: clinical implications of integrative physiology. Clin Exp Pharmacol Physiol 2013;40:106122.

8 Hansell P, Welch WJ, Blantz RC, Palm F: Determinants of kidney oxygen consumption and their relationship to tissue oxygen tension in diabetes and hypertension. Clin Exp Pharmacol Physiol 2013;40:123-137.

-9 Legrand M, Mik EG, Johannes T, Payen D, Ince C: Renal hypoxia and dysoxia following reperfusion of the ischemic kidney. Mol Med 2008; $14: 502-516$.

10 Legrand M, Bezemer R, Payen D, Ince C: The role of renal hypoperfusion in the development of renal microcirculatory dysfunction in endotoxemic rats. Intensive Care Med 2011; 37:1534-1542.

11 Johannes T, Mik EG, Ince C: Nonresuscitated endotoxemia induces microcirculatory hypoxic areas in the renal cortex in the rat. Shock 2009;31:97-103.

12 Rosenberger C, Rosen S Heyman SN: Renal parenchymal oxygenation and hypoxia aadaption in acute kidney injury. Clin Exp Pharmacol Physiol 2006;33:980-988.
3 Abdelkader A, Ho J, Ow C, Eppel GA, Rajapakse NW, Schlaich MP, Evans RG: Renal oxygenation in acute renal ischemia-reperfusion injury. Am J Physiol Renal Physiol 2014; 306:F1026-F1038.

14 Wang W, Jittikanont S, Falk SA, Li P, Feng L, Gengaro PE, Poole BD, Bowler RP, Day BJ, Crapo JD, Schrier RW: Interaction among nitric oxide, reactive oxygen species, and antioxidants during endotoxemia-related acute renal failure. Am J Physiol Renal Physiol 2003;284:F532-F537.

15 Yoshioka T, Ichikawa I: Glomerular dysfunction induced by polymorphonuclear leukocyte-derived reactive oxygen species. Am J Physiol 1989;257:F53-F59.

16 Vaziri ND, Dicus M, Ho ND, Boroujerdi-Rad L, Ram K, Sindhu RK: Oxidative stress and dysregulation of superoxide dismutase and NADPH oxidase in renal insufficiency. Kidney Int 2003;63:179-185.

17 Koyner JL, Sher Ali R, Murray PT: Antioxidants. Do they have a place in the prevention or therapy of acute kidney injury? Nephron Exp Nephrol 2008;109:e109-e117.

18 Ware K, Qamri Z, Ozcan A, Satoskar AA, Nadasdy G, Rovin BH, Hebert LA, Nadasdy T, Brodsky SV: N-acetylcysteine ameliorates acute kidney injury but not glomerular hemorrhage in an animal model of warfarin-related nephropathy. Am J Physiol Renal Physiol 2013;304:F1421-F1427.

9 Sadat U, Usman A, Gillard JH, Boyle JR: Does ascorbic acid protect against contrast-induced acute kidney injury in patients undergoing coronary angiography: a systematic review with meta-analysis of randomized, controlled trials. J Am Coll Cardiol 2013;62:2167-2175.

20 Schwartz D, Mendonca M, Schwartz I, Xia Y, Satriano J, Wilson CB, Blantz RC: Inhibition of constitutive nitric oxide synthase (NOS) by nitric oxide generated by inducible NOS after lipopolysaccharide administration provokes renal dysfunction in rats. J Clin Invest 1997;100: 439-448.

21 Legrand M, Almac E, Mik EG, Johannes T, Kandil A, Bezemer R, Payen D, Ince C: L-NIL prevents renal microvascular hypoxia and increase of renal oxygen consumption after ischemia-reperfusion in rats. Am J Physiol Renal Physiol 2009;296:F1109-F1117.
22 Johannes T, Mik EG, Klingel K, Dieterich HJ, Unertl KE, Ince C: Low-dose dexamethasone supplemented fluid resuscitation reverses endotoxin-induced acute renal failure and prevents cortical microvascular hypoxia. Shock 2009;31:521-528.

23 Wang Z, Holthoff JH, Seely KA, Pathak E, Spencer HJ, Gokden N, Mayeux PR: Development of oxidative stress in the peritubular capillary microenvironment mediates sepsisinduced renal microcirculatory failure and acute kidney injury. Am J Pathol 2012;180: 505-516.

24 Legrand M, Kandil A, Payen D, Ince C: Effects of sepiapterin infusion on renal oxygenation and Early Acute Renal Injury Following Supra-Renal Aortic Clamping in Rats. J Cardiovasc Pharmacol 2011;58:192-198.

25 Payen D, de Pont A, Sakr Y, et al: A positive fluid balance is associated with a worse outcome in patients with acute renal failure. Crit Care 2008; $12:$ R74.

26 Arikan AA, Zappitelli, M, Goldstein SL, et al: Fluid overload is associated with impaired oxygenation and morbidity in critically ill children. Pediatr Crit Care Med 2012;13:253258.

27 Legrand M, Mik EG, Balestra GM, Lutter R, Pirracchio R, Payen D, Ince C: Fluid resuscitation does not improve renal oxygenation during hemorrhagic shock in rats. Anesthesiology 2010;112:119-127.

28 Almac E, Aksu U, Bezemer R, Jong W, Kandil A, Yuruk K, Demirci-Tansel C, Ince C: The acute effects of acetate-balanced colloid and crystalloid resuscitation on renal oxygenation in a rat model of hemorrhagic shock. Resuscitation 2012;83:1166-1172.

29 Khan R, Kirschenbaum LA, Larow C, et al The effect of resuscitation fluids on neutrophil-endothelial cell interactions in septic shock. Shock 2011;36:440-444.

30 Ince C, Groeneveld ABJ: The case for $0.9 \%$ $\mathrm{NaCl}$ : is the undefendable, defensible? Kidney Int 2014, DOI: 10.1038/ki.2014.193.

31 Yunos N, Bellomo R, Hegarty C, Story D, Ho L, Bailey M: Association between a chlorideliberal vs. chloride-restrictive intravenous fluid administration strategy and kidney injury in critically ill adults. JAMA 2012;308:15661572 .
The Role of Renal Microcirculatory Dysfunction in the Pathogenesis of AKI
Nephron Clin Pract 2014;127:124-128 DOI: $10.1159 / 000363203$ 
-32 Ince C: Microcirculatory guided fluid therapy. Curr Opin Crit Care 2014;20:301-308.

- 33 Gomez H, Ince C, De Backer D, Pickkers P, Payen D, Hotchkiss J, Kellum JA: A unified theory of sepsis-induced acute kidney injury: inflammation, microcirculatory dysfunction, bioenergetics, and the tubular cell adaptation to injury. Shock 2014;41:3-11.

-34 Patil NK, Parajuli N, MacMillan-Crow LA, Mayeux P: Inactivation of renal mitochondrial respiratory complexes and manganese superoxide dismutase during sepsis: mitochondria-targeted antioxidant mitigates injury. Am J Physiol Renal Physiol 2014;306:F734F743.

35 Echtay KS, Esteves TC, Pakay JL, et al: A signalling role for 4-hydroxy-2-nonenal in regulation of mitochondrial uncoupling. EMBO J 2003;22:4103-4110.
36 Molitoris BA, Sutton TA: Endothelial injury and dysfunction: role in the extension phase of acute renal failure. Kidney Int 2004;66: 496-949.

37 Salmon AHJ, Satchell SC: Endothelial glycocalyx dysfunction in disease: albuminuria and increased microvascular permeability. J Pathol 2012;226:562-574.

38 Singh A, Ramnath RD, Foster RR, Wylie EC, Fridén $\mathrm{V}$, et al: Reactive oxygen species modulate the barrier function of the human glomerular endothelial glycocalyx. PLoS One 2013;8:e55852.

39 Adembri C, Sgambati E, Vitali L, Selmi V, Margheri M, Tani A, Bonaccini L, Nosi D, Caldini AL, Formigli L, De Gaudio AR: Sepsis induces albuminuria and alterations in the glomerular filtration barrier: a morphofunctional study in the rat. Crit Care 2011;15:R277.
40 Molitons B, Sandor D, Dahl RH: Ischemiainduced loss of epithelial polarity: role of the tight junction. J Clin Invest 1989;1334-1339.

41 Hanner F, Sorensen CM, Holstein-Rathlou $\mathrm{NH}$, Peti-Peterdi J: Connexins and the kidney. Am J Physiol Regul Integr Comp Physiol 2010;298:R1143-R1155.

42 Johannes T, Ince C, Klingel K, Unertl KE, Mik EG: Iloprost preserves renal oxygenation and restores kidney function in endotoxemia-related acute renal failure in the rat. Crit Care Med 2009;37:1423-1432.

43 Almac E, Johannes T, Bezemer R, Mik EG, Unertl KE, Groeneveld ABJ, Ince C: Activated protein $\mathrm{C}$ ameliorates impaired renal microvascular oxygenation and sodium reabsorption in endotoxemic rat. Intensive Care Med Exp 2013, DOI: 10.1186/2197-425X-1-5. 